\section{A REVIEW PAPER ON SEO FOR RANKING AND EFFECTIVENESS TECHNIQUES IN CONTEXT OF GOOGLE SEARCH ENGINE}

KEY WORDS: Search Engine,

SEO, Website Ranking, SEO

Techniques, Google ranking, robots file.
Mr. Amit K. Patel

Dr. Kishor H. Atkotiya*
Assistant Professor Department of Computer Science \& I.T. Shree M.V.\& N.V. Virani Science College, Rajkot

Professor \& Head, Department of Statistics Saurashtra University, Rajkot *Corresponding Author

In recent era Web Search Engine is very important in day to day life. But now it is quite difficult to get appropriate result in terms of your search query. Due to number of website is quite large so it is quite tough task to give proper result. The aim of this paper is to consider various techniques for SEO Ranking in context to Google Search Engine. It covers on page optimization and off page optimization which is very important factor about Search engine optimization.

\section{INTRODUCTION}

We all know that recently numbers of internet user are increased as we are living in a technological era. Everyone from school to business all are using internet as per their need. So now it is very complex task to deliver information which is relevant to your search. We all know that billion of web portal are currently exist and more than ten thousand website are build regularly. In this complex structure it is quite difficult to rank our new comers website in comparison to list of existing website. There are number of search engine are indexing website out of them we have studied only Google search engine regarding how they are giving important to any web portal or which are the factors which can help anyone to rank there website. We were gone through number of various already research which is from 2000 to 2019 . On basis of those papers we have find out certain common things and common techniques which are followed by all the search engine. Below is some of the literature survey that is made by us so we have list out here.

\section{LITERATURE SURVEY}

Below is some of the literature survey that we have made before going to any conclusions.

1) P. Chahal, M. Singh and S. Kumar "Ranking of Web Documents using Semantic Similarity": This paper consist of various search result which will be derived concept of the semantic similarity and EMD concept.

2) P. Rani and Er. S. Singh, "An Offline SEO (Search Engine Optimization) Based Algorithm to Calculate Web Page Rank According to Different Parameters": This paper is all about various algorithm based ranking system which are consider by google.

3) N. Batra, A. Kumar, Dr. D. Singh and Dr. R.N. Rajotia "Content Based Hidden web Ranking Algorithm (CHWRA)" : In this paper more important is given to content rather than any on page or off page algorithm.

\section{SEARCH ENGINE AND HOW ITWORISS?}

Every Search engine has their own features and their own way to produce result. Below we are going to know how they work and how you will get result of you search query. We have mentioned some of the important details about it. Search Engine is a kind of web portal which is design to indexing all web portals and set their result on priority of their algorithm. As we know there are list of the search engine like Google, Yahoo, MSN, AltaVista etc. As we have talked number of search engine are currently in action mode but out of them google is one of the widest used search engine. Most of search engine are following common techniques i.e on page SEO and Off Page SEO. Moreover every search engine has their own web master tool in order to inform their changes to their appropriate search engine. We have analyzing the Google search engine on web only. Any search engine is using various techniques that are listed as below.

1. Crawling:It is a process of Search engine to enter any web portal in their search list.

2. Indexing [1]: This process comes after crawling process here they are indexing website in their search engine.

3. Processing: Here Search engine indexing their pages in their database on basis of their own algorithm.

4. Calculate Relevancy: Internally indexing their content on basis of their relevancy.

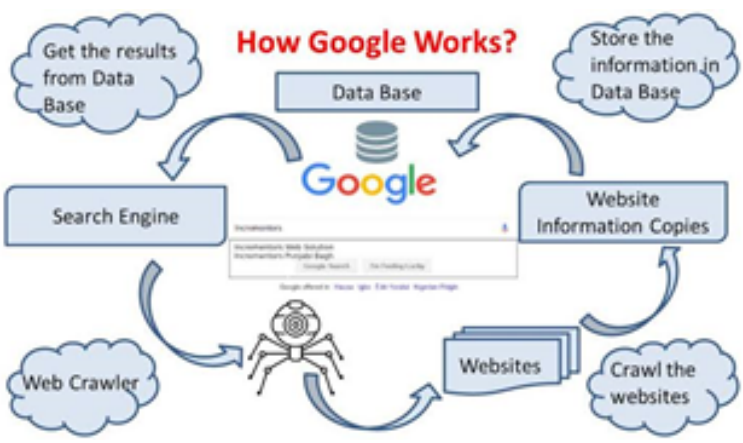

\section{RANKING TECHNIQUES OF SEARCH ENGINE}

There are number of way to rank your site in various search engine. But here we have provided some of the technique that can help to rank web portal in google search. SEO ranking can be done by many ways but it can be divided in mainly two ways which are described as below.

1 On Page Optimization: Here all the important factor of any website such as Page title, Designing home page in efficient way which will help to index and crawling in Google search engine. Some of the important List is described as below.

a. Title : it is very important for searching factor because Google will indexing any page on basis of their relevancy of title

b. Meta Description: One another important factor of on page optimization is meta description. Here the content will be relevant to your article and it should be provided.

c. Meta Keyword: This section covers a important factor about your article which should be provided on basis of their popularity on existing search engine.

d. Heading Tag: Here you need to use various Heading Tags from $\mathrm{Hl}$ to $\mathrm{H5}$ [3]. All heading tag has their own important and on basis of this tags Google are indexing their results.

e. Image: Normally if there is a one image in each article it will be more helpful to Google to ranking any website. One more thing it must have alt tags 
f. Sitemap: Sitemap is a kind of thing which will inform Google that we have this much of pages so that will help to indexing their page in search engine quite quickly in compare to website which doesn't have any sitemap.

g. Robots : It is also used to restrict some URL's to index in google by providing list of the urls in robots.txt files.

2 Off Page Optimization: Here it means link of web page which is listed in reputed web portal which has very high domain authority as well as various forum that will help to upward result in Google search engine. Off page SEO [4] consider following things to help you outrank.

a. Link Building:Without process of link building it is hard to rank in Google. So in this process you need to find out various high authority web portals which is of your category and where you can list out your web portal. If a web portal like news or forum will publish your article it will be easier to rank in Google [5].

b. Comments: In the beginning comment was one of the powerful way to rank in Google but now it is quite outdated so you can have a way but it's batter to avoid this kind of off page seo.

c. Social Networking: This section is also one of the important factors of off page optimization. Here you can have published your various content in platform such as instagram, facebook etc.

d. Blogging: You can have your own portal in various web portal such as BlogSpot where you can provide you all articles which you have published.

e. Google My Business service: Here you can list out your business which will be helpful to highlight your business too.

\section{BENEFITS AND DRAWBACKS OF SEO}

Every system has their own loopholes so we have bifurcated here which should be consider by the person who is doing SEO of any website.

1) You can rank in first pages of Google.

2) You will have more traffic so your business will be more popular.

3) As you have more traffic you will have more clients will increase your revenue at the end of the year.

4) It is one of the cost effective marketing strategy[6]

Some of the Drawbacks

1) There is no any surety to rank your website by following both on page and off page SEO techniques.

2) Every day you need to update your web portal to rank

3) Sometime you will have penalty in website due to Black Hat SEO techniques [7].

\section{TIPS TO IMPROVE GOOGLE RANKING OF AWEBSITE}

There are few tips which will help to rank in Google.

1) Mostly search engine have their own weight age in title tag so if you follow guideline of title tag that it will be more helpful to rank in search engine. For example if your site is related to shopping use Shopping in title of website.

2) Always use those words in your first 250 word paragraph which will have more searching in Google[8]. But you should not do too much stuffing.

3) After all content is a king to rank any website it should not be copy paste from any other existing website in Google.

4) Write various articles about your website in various forum and blogging [9] platform which will help to rank.

5) It is better to update content of your website frequently.

6) Google like to have interlinked content so it is batter to link with related content.

7) Server is also one of the key factor of any website it should have very less time to respond. In short page speed will be helpful to ranking any website in google

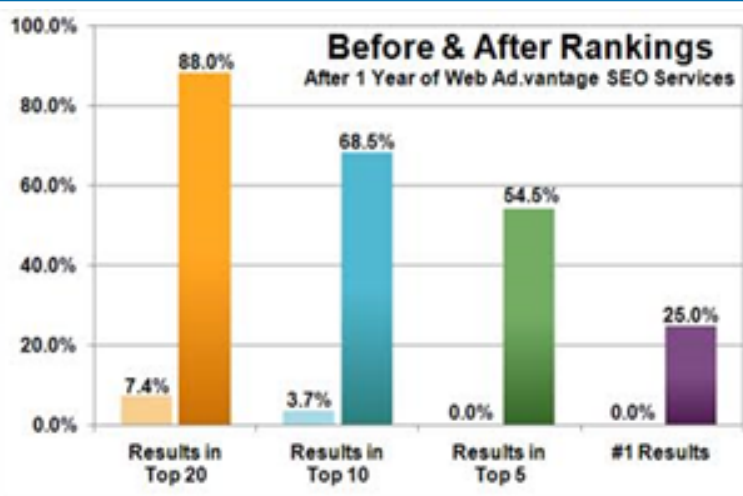

\section{CONCLUSION}

In the end, I conclude with various Search engine techniques which will help to make a ranking in google search engine.We all know any product which is not so famous in internet that will be quite difficult to famous world wide. Internet is only a medium which will helpful to increase you sell in globe. Internet will make a world in a small packet in terms of marketing. This research paper is on basis of on page [10] and off page techniques. By following above techniques a person who have quite knowledge of marketing can have a chance to ranking their web site in google. Moreover we have covered various basic process of ranking like indexing, sitemap, robots file etc.

\section{FUTUREWORKS}

As a further we have decided to learn various techniques which is useful to those who are making SEO. Furthermore we have planned to make a tool to identify the reasons which are helpful to anyone for ranking website in particular google search engine. In future we have plain to make a web based and window based tool to introduced over service.

\section{REFERENCES}

[1] Edgar Damian Ochoa: An Analysis of the Application of selected SEO techniques and their effectiveness on Google's search ranking algorithm, California state university,Northridge, May'2012 - csun-dspace.calstate.edu.

[2] Najam Nazar: Exploring SEO Techniques for Web 2.0Websites, Department of Computer Science and Engineering Chalmers University of Technology, Sweden, June 2009, Publikationen registrerades 2009-08-25. Den Andrade's senast 2018-04-04,Examiner: C. Carlsson

[3] Khalil ur Rehman and Muhammad Naeem Ahmed Khan: The Foremost Guidelines for Achieving Higher Ranking in Search Results through Search Engine Optimization, International Journal of Advanced Science and Technology,Vol.52,March, 2019.

[4] K.Chiranjeevi, K.Archana and J.Pradeep Kumar, "Design and Implementation of a Cost Effective Ranking Adaptation Algorithm", ISROSET-International Journal of Scientific Research in Computer Science and Engineering, Volume-01, Issue-05, Page No (24-24), Sep-Oct 2019.

[5] http://www.beginnersbloggingcoach.com/let-me-explainblogging-andwhy-you-should-have-a-blog/878

[6] http://webdesign.about.com/od/seo/a/why_use_hl_for_seo.htm

[7] M. Cui, S. Hu "Search Engine Optimization Research for Website Promotion" Information Technology, Computer Engineering and Management Sciences (ICM), 2011 International Conference on Vol.4, 2019 IEEE, DOI 10.1109/ICM.2019.308 Page(s): $100-103$

[8] H. Dubey, Prof. B. N. Roy "An Improved Page Rank Algorithm based on Optimized Normalization Technique" (IJCSIT) International Journal of Computer Science and Information Technologies, Vol. 2 (5), 2011 , Pages(s): 2183-2188

[9] A. Jain, R. Sharma, G. Dixit and V. Tomar, "Page Ranking Algorithms in Web Mining, Limitations of Existing methods and a New Method for Indexing Web Pages" Communication Systems and Network Technologies (CSNT), 2013 International Conference on, 2013 IEEE, DOI 10.1109/CSNT.2019.137 Page(s):640-645

[10] P. Chahal, M. Singh and S. Kumar "Ranking of Web Documents using Semantic Similarity" Information Systems and Computer Networks (ISCON), 2013 International Conference on 2013 IEEE, DOI 10.1109/IC ISCON. 2013.6524191 Page(s): 145 - 150 